\title{
IMPACT OF ENDEMICITY OF ASCARIASIS ON DIAGNOSIS OF ACUTE APPENDICITIS
}

\author{
Naveed Ahmed, Mian Sarfraz Gul*, Hafiz Khalid Pervaiz, Iftikhar Ahmed**, Mujahid Zulfiqar Ali, Shafaqat Ali**
}

Combined Military Hospital Quetta/National University of Medical Sciences (NUMS) Pakistan, * Muhammad College of Medicine, Peshawar Pakistan, **Pak Emirates Hospital / National University of Medical Sciences (NUMS) Rawalpindi Pakistan, ***Pakistan Naval Ship Shifa Hospital, Karachi Pakistan

\section{ABSTRACT}

Objective: To determine the impact of endemicity of ascariasis in the manifestation of acute appendicitis.

Study Design: Prospective observational study.

Place and Duration of Study: General Surgery Department, Combined Military Hospital Skardu, from May 2012 to Apr 2015. Methodology: Patients presenting with symptoms of acute appendicitis were included in the study. Patients were diagnosed after taking detailed history, clinical examination and blood chemistry. All the patients underwent open appendectomy under general anesthesia. Per-operatively presence of worms was assessed in terminal ileum and after that in the lumen of the appendix initially by palpation and then by opening its lumen after it was removed. Histopathologic diagnosis could not be confirmed due to its non-availability as the surgeries were performed in a remote and resource constraint area of the country.

Results: A total of 224 patients were included in the study. Out of these, 143 (63.8\%) were male and 81 (36.1\%) female patients. The mean age of patients was $22 \pm 6$ years. Per-operatively, 21 (9.3\%) patients had worms in both ileum and appendicular lumen while $22(9.8 \%)$ patients had worms only in the terminal ileum and there were no worms seen in either ileum or appendix in $181(80.8 \%)$ patients.

Conclusion: There is a relation of parasitic infestation especially Ascaris lumbricoides in the manifestation of acute appendicitis in endemic areas.

Keywords: Appendicitis, Appendectomy, Ascariasis, Infestation.

How to Cite This Article: Ahmed N, Gul MS, Pervaiz HK, Ahmed I, Ali MZ, Ali S. Impact of Endemicity of Ascariasis on Diagnosis of Acute Appendicitis. Pak Armed Forces Med J 2021; 71(5): 1567-1570. doi: https://doi.org/10.51253/pafmj.v71i5.5694

This is an Open Access article distributed under the terms of the Creative Commons Attribution License (https://creativecommons.org/licenses/by-nc/4.0/), which permits unrestricted use, distribution, and reproduction in any medium, provided the original work is properly cited.

\section{INTRODUCTION}

Acute appendicitis is one of the most frequent abdominal surgical emergencies worldwide. ${ }^{1}$ Lifetime incidence of acute appendicitis is $7 \%$ which is at its peak in second decade of life. ${ }^{2}$ It is a mucosal inflammation of vermiform appendix, which is a blind ending tube attached at posterolateral junction of caecum. Clinically it presents initially as pain in umblical region which later on migrates to right iliac fossa, nausea, vomiting and anorexia. ${ }^{3}$ Regarding the aetiology of acute appendicitis, there is no unifying hypothesis. Yet there are certain factors that can contribute towards acute inflammation of appendix like luminal obstruction, decreased dietary fibre, increased consumption of refined carbohydrates and familial propensity. ${ }^{4}$ Causes of appendicular luminal obstruction can be many. It can result from faecolith, lymphoid hyperplasia and foreign bodies. ${ }^{5}$ Parasitic infestation leading to obstruction of appendicular lumen resulting in edema, super added bacterial infection and necrosis is another rare but known cause of right iliac fossa pain in people living in

Correspondence: Dr Naveed Ahmed, Classified Paediatric Surgeon, Combined Military Hospital, Quetta Pakistan

Received: 17 Oct 2020; revision received: 27 Apr 2021; accepted: 03 May 2021 endemic areas. ${ }^{6,7}$

The parasitic infestation of appendicular lumen can be asymptomatic most of the times. ${ }^{8}$ Many parasites have been identified infesting the vermiform appendix; including Ascaris lumbricoides, Enterobius vermicularis, Schistosoma spp, Oxyuris vermicularis (pinworm) and Entamoeba histolyica. ${ }^{9}$ This study was carried out in Skardu, which is endemic area for Ascaris lumbricoides. This parasite is notorious for wandering in different parts of the body but it mainly involves the biliary and intestinal tract including appendix. ${ }^{10}$ A lumbricoides has a predilection for terminal ileum in gastrointestinal tract where it can either pass on through ileo cecal valve without causing many symptoms or it can make a large bolus of worms which can either obstruct or rarely perforate the intestine or it can even get embedded in the appendicular lumen and obstruct it resulting in symptomatology of acute appendicitis. A very high index of suspicion is required if one is not to miss the diagnosis like acute appendicitis especially in the endemic areas. Skardu is a remote city in northern areas of Pakistan in the province of Gilgit-Baltistan. The endemicity of A. lumbricoides in this area is a major health burden because, on one hand, it causes many diseases like intestinal ascariasis and anemia and on 
the other hand local population have many false beliefs which donot let them adapt the hygienic measures like using the boiled drinking water. One such belief is that spring water cannot be contaminated being a natural reservoir. Another such belief is that worms in the body especially intestines are good for health as they are a natural source of getting rid of the germs in the intestine.

The rationale behind this study was to elaborate the correlation and management of Ascaris infested appendicitis in the population of Skardu; as there is no local study carried out on this before in Pakistani literature. The findings of this study will help in gathering data for establishment of evidence based practices regarding management of this disease in local population. At the same time, it may help to devise the guidelines to educate the local population regarding the importance of hygienic measures like using boiled drinking water and improve primary health care system for prevention of such diseases.

\section{METHODOLOGY}

This prospective observational study was carried out at the department of General Surgery, Combined Military Hospital, Skardu, from May 2012 to April 2015 after ethical review committee approval (reference number $003 / 2020$, case number $1015 /$ adm dated $30^{\text {th }}$ October 2020). A written consent was taken from all patients included in the study.

Inclusion Criteria: All the patients of both genders presenting with symptoms of acute appendicitis.

Exclusion Criteria: Non-consenting patients were excluded.

Patients were diagnosed after taking detailed history, clinical examination and blood chemistry that included full blood count. Other investigations like hepatitis profile, renal profile, coagulation profile, chest $\mathrm{x}$-ray and elctrocardiography were done according to hospital policy, age and comorbids of the patient.

After diagnosis, patients were admitted and kept nil by mouth. Antibiotics, analgesics and intravenous fluids were started. Patients were prepared for surgery. After written informed consent, all the patients were operated in general anesthesia in supine position. All patients underwent open appendectomy by a consultant surgeon. Per-operatively, presence of worms was assessed in small intestine by delivering terminal ileum in the wound and after that in the lumen of the appendix initially by palpation and then by opening its lumen after it was removed (Figure-1). Demographic



Figure-1: Ascaris lumbricoides in appendicular lumen.

details like age, gender and per-operative findings regarding worms were recorded in a pre-designed proforma. Histopathologic diagnosis of appendicitis could not be confirmed as the surgeries were performed in a remote and resource constraint area of the country where the facility of histopathology was not available. Postoperatively, patients were discharged once started tolerating oral diet. On discharge, patients were advised anthelmintics and hygienic measures depending upon the operative findings. Postoperatively patients were followed up at 10 days for wound assessment and removal of stitches.

Collected data were analyzed. Data were entered and analyzed by using SPSS-23. Mean and standard deviation were calculated for age. Percentages were computed for quantitative variables like gender and presence or absence of worms

\section{RESULTS}

A total of 224 patients were included in the study who underwent appedectomy. Out of these, $143(63.8 \%)$ were male and $81(36.1 \%)$ female patients as shown in the Figure-2. The mean age of patients was

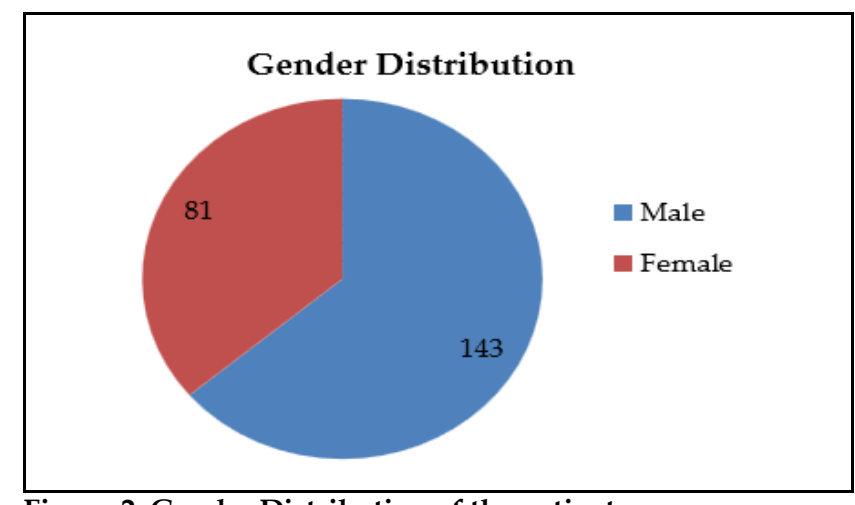

Figure-2: Gender Distribution of the patients.

$22 \pm 6$ years. Per-operatively, $21(9.3 \%)$ patients had worms in both ileum and appendicular lumen while 
$22(9.8 \%)$ patients had worms only in the terminal ileum and there were no worms seen in either ileum or appendix in $181(80.8 \%)$ patients, as shown in the Figure-3.

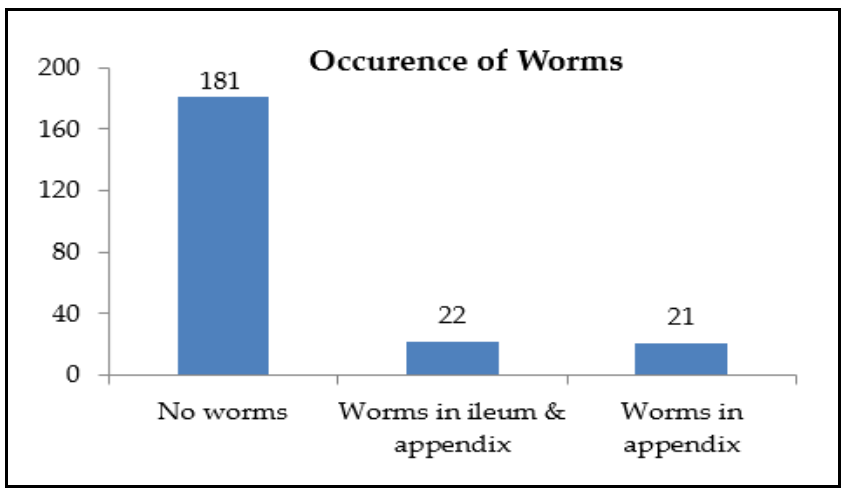

Figure-3: Occurrence of worms.

\section{DISCUSSION}

Ascaris lumbricoicoides is commonly known as roundworm. It is estimated that a quarter of the world's population is effected with it being the commonest intestinal nematode to infect the human. Abdominal ascariasis has a broad spectrum of presentations in endemic population. The wandering nature of this parasite is mainly the reason for wide variety of symptomatology ranging from mild abdominal pain to surgical emergency warranting immediate intervention. ${ }^{10}$ Larvae of Ascaris mainly cause the respiratory symptoms but its adult form is responsible for gastrointestinal symptoms. Acute appendicitis is one of the manifestations of abdominal ascariasis. Similarly, an asymptomatic appendicular lumen infested with ascaris parasite can also be found. It should be kept in differential diagnosis of pain right iliac fossa in endemic population. ${ }^{11}$ Appendectomy procedure provides an opportunity to diagnose intestinal ascariasis in the patient who was otherwise having a silent course of disease. We probed every appendectomy specimen grossly in our duration of study to see the impact of endemicity of ascariasis on diagnosis of acute appendicitis.

Surprisingly, the association between ascaris infestation and acute appendicitis is not new. In fact, it has been known for more than a century. In British Medical Journal, 26 $6^{\text {th }}$ March 1906, two cases were reported who presented with clinical features of acute appendicitis. Their symptoms subsided after some time when they passed round worms in their stools. With the improvement of their symptoms, it was hypothesized that round worms might have entered the appendicular lumen partially, caused inflammation, sym- ptoms suggestive of acute appendicitis and later on passed, and the symptoms resolved. In the Pakistan Armed Forces Medical Journal, a case was narrated in which a 14 years old girl was suffering from intestinal helminthiasis and was passing round worms frequently. On administration of anthelmintics, she developed abdominal pain mainly in the right iliac fossa along with vomiting and fever. The condition lasted for two days and then she suddenly died. On postmortem examination, her thoracic organs were found to be normal. However, examination of peritoneal cavity revealed that appendix was grossly swollen with engorged vessels. There were areas of fibrinous exudates ${ }^{12}$. On opening the appendix, Ascaris lumbricoides was found to be firmly embedded in the appendicular lumen and was thought to be the cause of the symptoms. Many other round worms were also seen in the lumen of the small intestine ${ }^{12}$. These findings support the findings in our study in which ascariasis and acute appendicitis are found to be associated to each other.

A study was conducted in local paediatric population of Skardu for worm infestation which revealed that A. lumbricoides is the most frequently prevailing parasite. ${ }^{13}$ Their stool examination was done for presence of ova and cysts of parasites. Out of total 250 children, stools of $76.8 \%$ were found to be positive and this parasitic infestation was attributed to use of stream water, poor hygiene, low level of maternal education and rural living.

Local literature search for appendicular infestation with A. lumbricoides in Pakistani population reveals no publications. Arham et al, published their experience of 471 appendectomies carried out in Banazir Bhutto Hospital, Rawalpindi. Only 15 (3.18\%) were found to have worm infestation. Enterobius vermicularis was the worm found in appendix in their study. ${ }^{14}$ They conducted their study in Pakistan's 4th largest metropolitan city situated adjacent to capital of the country, where people have good literacy rate, hygiene, socioeconomic status and healthcare facilities as compared to Skardu, which is a remote, and resource constraint area with poor population, lower literacy rate and healthcare infrastructure that is not up to the desired standards. Due to above mentioned reasons, in our study, out of 224 appendectomies, 43 (19.1\%) were found positive for infestation in small intestine and appendix.

Wani et al, shared their experience of appendicular ascariasis, in which they found 11 patients with appendicular ascaris worm infestation. Out of those 8 
$(72.7 \%)$ were incidentally found to have worm in lumen without appendicitis, while $4(27.2 \%)$ had appendicitis with luminal infestation. Their population size in comparison to our study population size was quite small as they only recruited children in their study, while in our study we probed every patient undergoing appendectomy irrespective of age. ${ }^{15}$

In America, a study was published to highlight the three common presentations of ascariasis in emergency settings. One of the three presentations was periappendiceal abscess which again speaks of likelihood of appendix to get effected with this parasite. ${ }^{16}$

There are also few published case reports from different parts of the world showing ascaris infested appendix as a cause of appendicitis. Few of those studies have been summarized in the Table in order to highlight the importance of the subject.

Table: Case reports on ascaris infested appendicitis.

\begin{tabular}{l|l}
\hline $\begin{array}{l}\text { Previous } \\
\text { Literature }\end{array}$ & Brief Description \\
\hline $\begin{array}{l}\text { Estibaliz } \\
\text { et } a l^{17}\end{array}$ & $\begin{array}{l}\text { In two cases parasitic infestation was found in } \\
\text { appendicular lumen. One was found to have } \\
\text { Enterobius Vermicularis and other was found } \\
\text { to have Ascaris Lumbricoides. In both cases } \\
\text { appendix was found to be inflammed. }\end{array}$ \\
\hline $\begin{array}{l}\text { Hoshang } \\
\text { et al }{ }^{18}\end{array}$ & $\begin{array}{l}\text { In one patient ascariasis was found to be the } \\
\text { cause of acute appendicitis. }\end{array}$ \\
\hline $\begin{array}{l}\text { Ghaedi } \text { et } \\
\text { al } 19\end{array}$ & $\begin{array}{l}\text { A case report in which appendicitis was due to } \\
\text { infestation by ascaris lumbricoides }\end{array}$ \\
\hline $\begin{array}{l}\text { Carrasco } \\
\text { et al }\end{array}$ & $\begin{array}{l}\text { Ascaris Lumbricoides was found to be the } \\
\text { cause of acute appendicitis in one patient. }\end{array}$ \\
\hline $\begin{array}{l}\text { Yazicioğlu } \\
\text { et } a l^{21}\end{array}$ & $\begin{array}{l}\text { Ascaris Lumbricoides was found in appendix } \\
\text { and caecum of a patient with appendicitis. }\end{array}$ \\
\hline
\end{tabular}

\section{CONCLUSION}

Our study indicates that there is a relation of parasitic infestation in the manifestation of acute appendicitis in endemic areas. (To frame the guide lines regarding appendicitis workup in such areas needs further studies to encompass the investigations including routine ultrasound, stool examination and histopathology as acute appendicitis can be a lead towards the diagnosis of parasitic infestation in otherwise silent cases). Furthermore, this study also indicates that how much burden this endemicity implies on the health infrastructure of an already compromised system.

\section{Conflict of Interest: None.}

\section{Authors' Contribution}

NA: Direct contribution, MSG: Data design, HKP: Interpretation of data, IA: Data conception, MZA: Data analysis, SA: Interpretation of data.

\section{REFERENCES}

1. Graff LG, Robinson D. Abdominal pain and emergency department evaluation. Emerg Med Clin North Am 2001; 19(1): 123-136.

2. Afuwape OO, Ayandipo OO, Soneye O, Fakoya A. Pattern of presentation and outcome of management of acute appendicitis: A 10-year experience. J Clin Sci 2018; 15(2): 171-175.

3. Téoule P, de Laffolie J, Rolle U, Reissfelder C. Acute appendicitis in childhood and adulthood: an everyday clinical challenge. Dtsch Arztebl Int 2020; 117(45): 764-774.

4. Hernández-Cortez J, De León-Rendón JL, Martínez-Luna MS, Guzmán-Ortiz JD, Palomeque-López A, CruzLópez N, et al. Acute appendicitis: literature review. Cir Gen. 2019; 41(1): 33-38.

5. Khan AA, Asghar AS, Ishaq M, Akhund IA. Appendicular diseases; Spectrum in surgical pathology. Professional Med J 2017; 24(8): 1114-1119.

6. Vagholkar K. Acute appendicitis in adults. Int Surg J 2020; 7(9): 3180-3186.

7. Fuentes-Ernult LV, Gálvez-Castillejos P, Molina-Villena AA, Zárate AC, Ivey-Miranda JB, De Giau-Triulzi LF, et al. Unusual findings in appendectomy: experience in a third level hospital with more than 1000 specimens. Surg Sci 2019; 10(11): 377-384.

8. Jonas L, Bombil I, Mannell A. Unusual histopathologies of the appendix. S Afr J Surg 2020; 58(3): 160-65.

9. Ibrahim IA, Bayoumy AM, Elnasr AO, Mohamed MR, Salah-ELdin SS. Role and incidence of parasitic infection in adult egyptian patients with acute appendicitis. Egyptian J Hosp Med 2018; 70(12): 2050-2057.

10. Margery J, Niang A. Adult ascaris worm passing from the mouth. Am J Trop Med Hyg 2011; 85(3): 395-404.

11. Altun E, Avci V, Azatçam M. Parasitic infestation in appendicitis. A retrospective analysis of 660 patients and brief literature review. Saudi Med J 2017; 38(3): 314-318.

12. Castellani A. Ascaris Lumbricoides As Cause Of Appendicitis. Br Med J 1906; 2(2379): 252-253.

13. Yousafzai US, Niazi SU. Worm infestation in children of Skardu. Pak Armed Forces Med J 2012; 62(3): 422-426.

14. Arham M, Arish M, Khan JS. Incidental parasitic infestations in surgically removed appendices and its association with inflammation. J Rawalpindi Med Coll 2018; 22(1): 47-49.

15. Wani I, Maqbool M, Amin A, Shah F, Keema A, Singh J. Appendiceal ascariasis in children. Ann Saudi Med 2010; 30(1): 63-66.

16. Valentine CC, Hoffner RJ, Henderson SO. Three common presentations of ascariasis infection in an urban Emergency Department. J Emerg Med 2001; 20(2): 135-139.

17. Echazarreta-Gallego E, Córdoba-Díaz de Laspra E, Mejia-Urbaez E, Hernáez-Arzoz A, Sánchez-Blasco L, Elía-Guedea M. Apendicitis y parásitos: a propósito de 2 casos. Rev Chil Cir 2016; 68(5): 373-375.

18. Hoshang MS, Alam T, Hamidi H, Rasouly N, Maroof S. Ascaris lumbricoides and acute appendicitis: a case report. Pak J Radiol 2016; 26(1): 23-25.

19. Ghaedi M, Pourdavood AH, Haghbeen M, Sepidkar AA, Foroughian M, Etezadpour M, et al. Ascaris worm incidentally found during the appendectomy: A case report of Parasitic Appendicitis. Int J Med Invest 2020; 9(3): 76-80.

20. Carrasco MR, Flores AG, Robinot DC. Dolor en la fosa iliaca derecha.apendicitis. No,ascaris lumbricoides. Acta Pediatr Espa 2017; 75(1): 33-36.

21. Yazicioğlu MB, Tiryaki Ç, Haksal MC, Çiftçi A, Yildiz SY. A rare cause of acute appendicitis, Ascaris lumbricoides: case report. Türkiye Klinikleri J Case Rep 2016; 24(1): 39-41. 